\title{
ESPAÑA Y EL EXPOLIO DE LAS COLECCIONES ARTÍSTICAS EUROPEAS DURANTE LA SEGUNDA GUERRA MUNDIAL: EL INFORME OFICIAL DE $1998^{12}$
}

SPAIN AND THE EXPOLIO OF THE EUROPEAN ARTISTIC COLLECTIONS DURING

THE WORLD WAR II: THE OFFICIAL REPORT OF 1998

\author{
José Manuel Serrano ${ }^{3}$ \\ Universidad de Antioquia \\ DOI: $10.17533 /$ udea.tempus.n7a08
}

\section{Resumen}

Este artículo analiza el informe oficial español de 1998 sobre el expolio de obras artísticas durante la segunda guerra mundial. Trata de enfocar cómo las autoridades españolas generaron un informe encargado a un académico con el fin de mostrar que las autoridades públicas estaban interesadas en este asunto. Sin embargo, el análisis demostrará que quedó muy lejos de sus objetivos.

Palabras clave: Expolio artístico, segunda guerra mundial, España, informe oficial

\begin{abstract}
This article analyzes the official Spanish report of 1998 on the plundering of artistic works during the Second World War. It tries to focus on how the Spanish authorities generated a report commissioned to an academic in order to show that public authorities were interested in this matter. However, the analysis will show that it was very far from its objectives.
\end{abstract}

Keywords: Artistic Plundering, Second World War, Spain, official report

\section{Introducción}

Es sumamente conocido el III Reich por su política expansiva que derivó en el inicio de la tragedia de la II Guerra Mundial, así como por la actitud excluyente y agresiva frente a otros pueblos y razas, principalmente los judíos. En los últimos setenta años se han escrito

\footnotetext{
${ }^{1}$ Este artículo es producto del proyecto de investigación El expolio artístico de Europa durante el Reich, 1939-1945: mecanismos, redes y agentes, aprobado por el SIU de la Universidad de Antioquia, y ejecutado de 2012 a 2017.

2 Artículo recibido el 11 de noviembre de 2017; aprobado el 02 de abril de 2018

${ }^{3}$ Doctor en historia por la Universidad de Sevilla. Profesor titular en la Universidad de Antioquia. Jmserranoalvarez@gamil.com
} 
miles de libros sobre la Alemania nazi, la II Guerra Mundial y una enorme variedad de elementos anexos a los doce años de gobierno de Hitler, entre 1933 y 1945. Las descripciones y estudios en estos campos han sido abrumadores ${ }^{4}$, y hoy por hoy, sabemos infinitamente más que los historiadores de los años 50 y 60 del siglo XX. De toda esa inmensa gama de estudios, sobresalen aquellos que están enfocados a la historia militar y a la política del III Reich. Prácticamente no hay operación militar que no tenga su monografía, como lo es cada uno de los aspectos referentes al gobierno nazi. Todo ello gracias a la desclasificación de una enorme masa documental desde los años 70, a la apertura de nuevos archivos (principalmente de Europa del este), y a la decidida acción de grupos de historiadores (fundamentalmente alemanes, británicos y norteamericanos) que han enfocado sus estudios dentro de una corriente general revisionista.

Esta corriente, que tiene un vector fundamentalista e incluso negacionista de los hechos, es en su mayor medida profundamente positiva ${ }^{5}$. Alejada de los estereotipos de los primeros historiadores del periodo, estos historiadores han enfocado los análisis de la etapa de 1933 a 1945 dentro de unos parámetros más amplios, por lo general interdisciplinares, y abiertos a interpretaciones flexibles, en la que se incluían incluso críticas abiertas hacia la política y actitud de los aliados durante la Segunda Guerra Mundial y años precedentes. Como resultado, en los últimos veinte años se han publicado análisis mucho más objetivos, interpretaciones que concatenaban aspectos entre diferentes Estados, y visiones del conflicto y sus causas que iban mucho más allá que la simple criminalización del régimen nazi, la sociedad alemana o la actitud de sus dirigentes. El resultado es esperanzador. Hoy en día la Alemania nazi está siendo enfocada en el conjunto de una crisis general de valores

\footnotetext{
${ }^{4}$ Solo a modo de indicación general, véase: Ian Kershaw, La dictadura nazi, (Madrid: Ed. Siglo XXI, 2004); Ian Kershaw, El mito de Hitler: imagen y realidad en el Tercer Reich, 1a ed, (Memoria crítica) (Barcelona: Crítica, 2012); Ian Kershaw, The Nazi dictatorship: Problems and perspectives of interpretation (Edward Arnold London, 1989); Götz Aly, La utopía nazi. Cómo Hitler compró a los alemanes (Barcelona: Crítica, 2008); Ian Kershaw, The Nazi State: An Exceptional State? (New Left Review Limited, 1989); Joachim C. Fest, Yo no: el rechazo del nazismo como actitud moral, Memorias y biografías (Taurus) (Madrid: Santillana Ediciones Generales, 2007); Ian Kershaw, «The essence of Nazism: form of fascism, brand of totalitarianism, or unique phenomenon?», I. Kershaw, The Nazi Dictatorship. Problems and Perspectives of Interpretation, 1993, 17-39; Ronald Gray, Hitler y los alemanes, Historia del mundo para jóvenes. Monografías 39 (Torrejón de Ardoz (Madrid): Akal, 1991); Roger Griffin, Modernismo y fascismo. La sensación de comienzo bajo Mussolini y Hitler, (Madrid: Akal, 2010).

${ }^{5}$ Daniela Baratieri, Mark Edele, y Giuseppe Finaldi, Totalitarian Dictatorship: New Histories (New York: Routledge, 2013); Ian Kershaw, Totalitarianism revisited: Nazism and Stalinism in comparative perspective (Cambridge: Cambridge University Press, 1994).
} 
tradicionales de la sociedad europea y occidental ${ }^{6}$, de la que el régimen nazi fue su exponente más agresivo (o uno de ellos), pero en ningún caso como un agente ajeno a profundos cambios de la sociedad del momento, que veía la alternativa autoritaria a los viejos sistemas democráticos como una salida casi natural, en algunos casos incluso concomitante con su tradición histórica.

Ahora bien, en este fresco contexto de estudios alternativo a las historias oficiales y a las interpretaciones simplistas, se ha dejado notar un vacío sorprendente. Los estudios sobre la expoliación de obras de arte entre 1939 y 1945, a pesar de ser abundantes, se han centrado casi exclusivamente en la mecánica del saqueo y robo de patrimonio en los distintos países ocupados (y en la propia Alemania), así como en la búsqueda tras la guerra de las obras desaparecidas. Sin obviar ni limitar su importancia, estos estudios dejan a un lado casi de manera general las implicaciones de los diferentes actores de este drama, en especial de los académicos. Igualmente, las redes clientelares asociadas a este robo han sido muy poco tratadas. Como resultado, la impresión general (excluyendo algunas excepciones) es que la eliminación de una enorme masa de obras de arte de manos de sus dueños o la enajenación del patrimonio cultural de los Estados ocupados fue obra de una élite muy reducida del partido nazi, liderada por Hitler quien, creyendo ser un artista, diseñó un plan general para "limpiar" Europa de arte impuro y degenerado, para imponer una visión germánica de la cultura, el arte y el patrimonio.

En esta dirección apuntaron las primeras significativas aportaciones historiográficas sobre el expolio en Europa ${ }^{7}$. Estas obras, así como otras de años relativamente recientes ${ }^{8}$,

\footnotetext{
${ }^{6}$ Niall Ferguson, La guerra del mundo: los conflictos del siglo XX y el declive de Occidente (1904-1953), 1a ed (Barcelona: Debate, 2007).

${ }^{7}$ Héctor Feliciano, El museo desaparecido: la conspiración nazi para robar las obras maestras del arte mundial (Barcelona: Planeta DeAgostini, 2006); Lynn H. Nicholas, El saqueo de Europa: el destino de los tesoros artísticos europeos durante el Tercer Reich y la Segunda Guerra Mundial (Barcelona: Ariel, 2007); Berthold Hinz y Joaquim Dols Rusiñol, Arte e ideología del nazismo (Valencia: Fernando Torres, 1978).

${ }^{8}$ Raphael Samuel, “Art and Power", History Workshop Journal 41 (1996): 250-253; Marjorie Agosín, “Art Under Dictatorship”, Agni, n.o 31/32 (1990): 33-36; Germany (Territory under Allied occupation, 1945- U. S. Zone) Office of Military Government y Hellmut Lehmann-Haupt, eds., Cultural looting of the «Ahnenerbe,» (Berlin, 1948); Peter Adam y AntonioPrometeo Moya, El arte del Tercer Reich, 1a ed (Barcelona: Tusquets, 1992); Alfred Werner, "Ernst Barlach: Artist under a Dictatorship", Art Journal 22, n.o 2 (1962): 81-87; Kenneth D. Alford, Hermann Göring and the Nazi art collection : the looting of Europe's art treasures and their dispersal after World War II (Jefferson: McFarland \& Company, Inc., Publishers, 2012).
} 
han destacado los aspectos más sombríos del proceso de uniformización cultural propuesto por los nazis, así como el debate entre arte degenerado, artistas perseguidos y arte racialmente puro. Igualmente, una enorme cantidad de investigaciones se ha centrado en las últimas dos décadas en localizar obras perdidas durante la guerra para ser devueltas a sus dueños o herederos, principalmente judíos. El panorama académico es, por tanto, sumamente positivo en lo que a estos aspectos se refiere.

Al concluir la Segunda Guerra Mundial pocos podían imaginar el inusitado saqueo al que la Europa de las artes y la cultura sometieron los alemanes durante la contienda. El III Reich inició en 1939 uno de los expolios culturales más intensos de la historia, mayor incluso del que protagonizó el adalid de la "libertad, igualdad y fraternidad" Napoleón, quien entre 1808 y 1814 saqueó y/o destruyó importantes colecciones de arte y monumentos históricos de Italia, Prusia o España 9 .

\section{España y el expolio}

En relación con esto, siendo España uno de los países que más sufrió el latrocinio napoleónico, y estando en el poder el general Francisco Franco tras su victoria en la Guerra Civil Española (1936-1939), hubiera sido lógico y deseable que el régimen español hubiera sido uno de los más suspicaces respecto de las intenciones alemanas durante la guerra mundial, máxime cuando era notorio en la vecina Francia, que desde 1940 los alemanes estaban procediendo a un saqueo sistemático del rico arte galo, y que España, con su no menos esplendoroso y variado patrimonio artístico y cultural, podría ser una víctima propiciatoria de las ansias alemanas por "depurar" el arte degenerado y hacerse con el control de obras "dignas" del paladar teutón. El fascismo, en este sentido, necesitaba también una depuración cultural como parte del programa regenerador social y político ${ }^{10}$. Sin embargo, sabemos desde la década de 1980, que el régimen colaboró de forma como mínimo pasiva, cuando no transigente, a los deseos alemanes de desviar obras hacia el territorio español, bien para esconderlas bien para cambiarlas por otras de más interés. Las

\footnotetext{
${ }^{9}$ El Expolio del Patrimonio Español durante la guerra de Independencia, Fundación Carlos Ballesta López, http://www.fundacioncarlosballesta.com/blog/el-expolio-del-patrimonio-espanol-durante-la-guerra-deindependencia

${ }^{10}$ Francisco Erice Sebares, Guerras de la memoria y fantasmas del pasado: Usos y abusos de la memoria colectiva (Oviedo: Eikasia, 2009), 118.
} 
voces que clamaban contra las actuaciones de España respecto de su participación en el saqueo de Europa provocaron una reacción del gobierno español que se vio forzado a solicitar un informe oficial al respecto.

El Informe en cuestión, denominado España y el expolio de las colecciones artísticas europeas durante la Segunda Guerra Mundial, publicado en diciembre de 1998, es un informe detallado y con diversos ejemplos sobre el expolio artístico acaecido durante la Segunda Guerra Mundial y el periodo de la postguerra, cuando los nazis saquearon enormes cantidades de patrimonio artístico de algunas naciones europeas. El centro de la investigación, desarrolla sus argumentos, en el papel que jugó la España de Franco, frente a la dispersión ilícita del material artístico expoliado por el régimen nazi. Su autor, Miguel Martorell Linares, profesor de la Facultad de Ciencias Políticas y Sociología, de la UNED, utilizó, para esta investigación, los informes de los servicios secretos norteamericanos y el Archivo del Ministerio de Asuntos Exteriores español (AMAE).

La estructura del informe está dividida en tres partes. Una primera, muestra un contexto global de la situación caótica, frente al expolio de las obras de arte presentes en Europa. Una segunda, se adentra en el tratamiento al problema que le dio España y su relación con los países Aliados. La última sección, examina algunos casos específicos, de ciudadanos acusados de ser partícipes del saqueo sistemático en toda Europa. Adicionalmente, el texto cuenta con dos apéndices, de los cuales el primero describe detalladamente la Situación de veintidós cuadros relacionados con Alois Miedl; y el segundo, versa sobre la Exposición de grabados alemanes de los siglos XIX y XX, ocurrida en Madrid en mayo de 1944.

\section{Primera parte: "La Segunda Guerra Mundial. Saqueo y dispersión de las colecciones artísticas europeas"}

El profesor Martorrell Linares, empieza mostrando los orígenes del expolio, donde menciona que, sus primeras víctimas fueron los judíos alemanes, sucedidos por los países ocupados por el régimen nazi. Según Martorrell, “en cifras globales, se expoliaron 
alrededor de 200.000 obras de arte"11. El objetivo alemán, era engrosar las listas artísticas de museos, dirigentes nazis y postores germanos y de países neutrales, que codiciaban estas obras de interés cultural. Por lo tanto, además del gobierno germano, el arte robado cayó en manos de saqueadores y contrabandistas, que expandieron su negocio por la Europa invadida o neutral, que se lucraba de la situación de inestabilidad. Otro participe del expolio, fue el Ejército soviético, que a medida que avanzaba su campaña, recolectaba el arte en poder de los nazis y lo enviaba a territorio ruso, donde se ocultaron tras el Telón de acero cantidades aun no conocidas de arte expoliado.

Ciudades, bibliotecas, archivos, museos y viviendas, de los estados ocupados, e incluso, ciudadanos alemanes perseguidos políticamente, fueron saqueados sistemáticamente, por una política construida por Alfred Rosenberg, quien creó para tal fin la Brigada del Reichsleiter Rosenberg "Einzatzstab Reichsleiter Rosenberg (ERR)", que tenía como función la enajenación de bibliotecas, archivos y obras de arte; además de una depuración de lo que él llamaba "arte degenerado". En informe hace especial hincapié en que Rosenberg, también fue el ejecutor del saqueo de gran cantidad de arte francés; de hecho, un informe de 1944 determinó una cifra de 21.903 piezas hurtadas del territorio galo por la ERR, de las cuales “10.890 eran cuadros, 583 esculturas, 2.477 muebles, 583 tapices y tejidos, 5.825 objetos de arte variados de pequeño tamaño (porcelanas, cristalerías, monedas, joyería, etc.) y 1.545 piezas de la antigüedad clásica u oriental. A la altura de agosto de 1945, la "Comisión francesa para la recuperación de obras de arte" estimó en 110 billones de francos el valor de las obras expoliadas por los nazis" ${ }^{2}$.

Una gran cantidad de arte robado iba a Alemania o Austria, y sus preferencias giraban en torno a viejos maestros alemanes, holandeses, flamencos, franceses e italianos. Los principales demandantes de arte fueron Hitler (interesado en arte de los viejos maestros y pintura alemana del siglo XIX) y Goering. Gran parte del material artístico fue hallado en minas de sal que lo protegían de la guerra. Los Aliados encontraron 6.755 pinturas de

\footnotetext{
${ }^{11}$ Miguel Martorell Linares, España y el expolio de las colecciones artísticas europeas durante la Segunda Guerra Mundial (Madrid: Ministerio de Asuntos Exteriores, 1998), 1.

12 Miguel Martorell Linares, España y el expolio, 2.
} 
viejos maestros, 230 acuarelas, 1.039 grabados, 95 tapices, 68 esculturas, 43 contenedores con pequeñas obras de arte y otros tantos 358 con libros de diversa procedencia ${ }^{13}$.

Para la selección de piezas se utilizaba personal calificado, que elegían que engrosaría el patrimonio del Reich. Además muchas de las transacciones realizadas con este material tenían apariencia de legalidad. Estos servicios se realizaban entre territorios ocupados, Alemania y los compradores nazis. Alois Miedl, tratante de arte y conexión directa de Goering en Francia, cumplió esta función a la perfección, siendo el principal artífice de la expoliación del país galo.

El ocaso de la guerra forzó la reubicación del arte expoliado. Su fácil transporte y cuantioso valor, eran beneficiosos para los nazis en el exilio, que tendría como lugar de destino los países neutrales, en donde la venta de dichas obras pasaría bastante desapercibida. "El problema, como indicaba un informe norteamericano, radicaba en que, a pesar de que "todos los signos apuntaban en esta dirección", dado el carácter clandestino de las actividades de contrabando, los Aliados sólo se encontraron "pruebas concluyentes" respecto a un limitado número de casos."14

Suiza, Francia y los territorios de Vichy, España, Portugal, y América, fueron algunos destinos. Suramérica fue un enorme redistribuidor de arte, adonde llegaban museos y coleccionistas en búsqueda de material. En diciembre de 1941, "el navío US Excalibur partió de Lisboa con 500 pinturas saqueadas en su bodega, camino de EEUU”. Además de la permeabilidad del territorio fronterizo, la valija diplomática transportó arte hacia países neutrales, que poseía inmunidad.

Según el autor del informe, es difícil calcular el tráfico de arte con los países neutrales, por la poca información que puede recabarse de ello. Sin embargo, se estima que “entre 29 y 46 millones de dólares el valor de la sobras de arte saqueadas que habían entrado en Suiza durante la guerra" "15, según un informe Aliado de 1945.

\footnotetext{
${ }^{13}$ Miguel Martorell Linares, España y el expolio, 2.

${ }^{14}$ Miguel Martorell Linares, España y el expolio, 3.

${ }^{15}$ Miguel Martorell Linares, España y el expolio, 4.
} 
Un informe de la Foreign Economic Administration, de agosto de 1945, relativo al arte saqueado por los nazis, señalaba lo poco de arte robado descubierto en España, y que el principal investigado era el alemán Alois Miedl. La misma posición tuvo la Art Looting Investigation Unit (ALIU), sección de la OSS (Strategic Service Office). "En mayo de 1946, la ALIU elaboró un informe en el que figuraban los nombres de 2.000 personas, pertenecientes a 11 países occidentales, ligadas a la compra de arte confiscado por el Tercer Reich. Del informe se desprende que, aunque España fue territorio de tránsito de obras de arte, el Estado español no estuvo implicado en el contrabando, y la participación española en el comercio de arte expoliado por los nazis fue relativamente pequeña y poco importante." "16 Seguidamente se asocian algunos personajes que estarían involucrados en el mercado de arte ilícito, dentro de España y que tenían una relación directa con Alemania.

Otra sección del informe, hace énfasis en la presión internacional sobre España. Primero se enuncian los parámetros jurídicos que los Aliados elaboraron para facilitar el retorno del arte expoliado. Por lo tanto, se menciona la Declaración número 18 de la ONU, del 5 de enero de 1943:

Las personas residentes en los países neutrales... su propósito de restituir a sus legítimos poseedores, tanto los tesoros públicos como el capital privado del que fueron desposeídos durante la ocupación de sus países". Por esta razón, declaraban "nulas y sin ningún valor toda clase de transferencias y operaciones de bienes, propiedades, derechos e intereses de cualquier clase... situados en los territorios que sufren o han sufrido la ocupación o control directo o indirecto de los países con los cuales están en guerra, o que pertenezcan o hayan pertenecido a personas naturales o jurídicas residentes en tales territorios". La advertencia también afectaba a "los bienes de todas las clases procedentes de saqueos o pillajes abiertos" y a las "operaciones que, bajo apariencia legal", pretendieran "encubrir aquellos, aun en el caso de que den a entender que se han efectuado voluntariamente". Esta última consideración es importante, pues muchas de las transacciones de obras de arte entre los alemanes y ciudadanos de países Aliados fueron sancionadas legalmente, pero efectuadas bajo coacción. ${ }^{17}$

Otra herramienta jurídica utilizada por los aliados fue la Resolución VI de la Conferencia de Bretton Woods, en julio de 1944, que España ratificó el 5 de mayo de 1945,

\footnotetext{
${ }^{16}$ Miguel Martorell Linares, España y el expolio, 4.

${ }^{17}$ Miguel Martorell Linares, España y el expolio, 4.
} 
recogía los parámetros de la anterior declaración. Otro organismo creado para la recuperación de arte fue el Consejo Aliado de Control (CAC).

Los aliados conformaron una política de recuperación de arte que operaba en lo siguiente: "Alemania tenía la obligación de restituir las obras de arte, libros y archivos históricos o artísticos que fueran identificados como parte del saqueo; todas las propiedades artísticas o históricas trasladadas a Alemania desde un país durante el período de ocupación serían tratadas como material expoliado; las reclamaciones sobre obras expoliadas debían ser realizadas por los gobiernos correspondientes, y no directamente por los ciudadanos afectados. Cada ciudadano debía recurrir a su gobierno; todos los países europeos debían congelar la exportación e importación de obras de arte, libros antiguos o archivos históricos y artísticos con el fin de impedir que el movimiento de estos materiales derivara en su desaparición"18

Segunda parte: El régimen de Franco ante el problema del arte expoliado: legislación y prácticas políticas

Durante la guerra, no existía un armazón legal que protegiera el patrimonio artístico a nivel internacional, ni acuerdos multilaterales. Solo se procedía a la requisa de obras de arte si eran encontradas sin licencia. En medio de la coyuntura internacional contraria al régimen español, el Gobierno de Franco se solidarizó en mayo de 1945 con la Resolución VI adoptada en la Conferencia financiera y monetaria de Bretton-Woods, forzado por la transformación del contexto internacional, incluso sin compartir algunos criterios Aliados de su contenido. Además, fueron los propios gobiernos Aliados quienes "decidieron que el problema del arte expoliado no sobrecargara la agenda del CAC, y que las gestiones al respecto quedaran en manos de las embajadas de cada país"19. Adicionalmente, "las referencias Aliadas al movimiento de obras de arte en España se limitaron a tres casos: la colección de cuadros de Alois Miedl, el supuesto robo de obras de arte de los locales de la Embajada alemana por parte de Hans Lazar y el material de la Exposición de grabados

\footnotetext{
${ }^{18}$ Miguel Martorell Linares, España y el expolio, 5.

${ }^{19}$ Miguel Martorell Linares, España y el expolio, 8.
} 
alemanes de los siglos XIX y XX"20. Martorrell Linares, afirma que varios señalados por los Aliados encontraron refugio temporal en España. Muchos de las solicitudes de extradición fueron denegadas y se entró en controversia en infinidad de ocasiones con las autoridades españolas por esta causa.

\section{Tercera parte: Estudio de casos}

\section{Alois Miedl y las veintidós pinturas del Puerto de Bilbao}

El informe afirmaba rotundamente lo siguiente: "Miedl estableció una de las principales redes alemanas de contrabando de obras de arte, con ramificaciones en Alemania, España, Francia, Suiza, Bélgica, Portugal y, por supuesto, Holanda, sede central de sus operaciones. La estrategia de Miedl consistía en comprar colecciones de pintura a ciudadanos judíos, que, coaccionados por el ambiente opresivo en los tiempos de la ocupación, vendían a precios inferiores al valor real de sus propiedades. No obstante, Miedl también compró obras de arte a holandeses y belgas que no tenían ascendencia hebrea. Herman Göering fue el destinatario principal de la mayor parte de sus compras"21. Sus lucrativas actividades fueron altamente rentables por la venta de colecciones, como la de Emile Renders, especializada en primitivos flamencos; o la colección de Jacques Goudstikker, que poseía más de un millar de cuadros, en su mayoría de maestros medievales y renacentistas holandeses, flamencos e italianos. Miedl, llevó a España cerca de "cuatro millones de pesetas en valores -acciones de diversas compañías y títulos de deuda de varios países-, un Ford, y veintidós cuadros (Apéndice 1), entre los que figuraban un Van Dyck, dos Corots, un Franz Hals y un David"22. Muchas de sus transacciones contaron con apoyo de una red de alto rango del régimen que no mencionaba nombres. Contra dicho sujeto, se enviaron numerosas solicitudes al Gobierno español, que tuvieron parcialmente efecto después de la firma de la Resolución VI de la Conferencia de Bretton Woods, donde éste y otros ciudadanos de los países del Eje u ocupados vieron bloqueados sus bienes e investigados.

\footnotetext{
${ }^{20}$ Miguel Martorell Linares, España y el expolio, 9.

${ }^{21}$ Miguel Martorell Linares, España y el expolio, 10.

${ }^{22}$ Miguel Martorell Linares, España y el expolio, 11.
} 
Luego de investigaciones y de las constantes declaraciones de inocencia de Miedl, las autoridades no habían conseguido pruebas concluyentes, ni bases para sostener las acusaciones contra el alemán. Todo este tire y afloje, relatado en el informe, finaliza el 24 de agosto de 1948, donde se desbloquean todos sus bienes, incluyendo las pinturas.

\section{El anticuario Pierre Lottier y Erich Schiffman, agente doble}

Según la Aliu, Pierre Lottier y Erich Schiffman eran socios en una empresa de muebles establecida en Barcelona, y traficaban en España con obras de arte y antigüedades procedentes de Francia, en especial, con porcelanas chinas; sin embargo no existe una constancia oficial de sus nexos. El análisis de este caso no es muy extenso.

\section{Hans Lazar y las obras de arte de la Embajada alemana}

Era un periodista, trabajador en la Sección de Prensa de la Embajada de Alemania en Madrid. Según los Aliados, él mantenía como residencia el edificio diplomático y fue partícipe del saqueo de material documental, herramientas y arte presentes en la Embajada; algo reclamado por los Estados Unidos. Su caso, después del análisis por los Aliados, fue declarado resuelto, saliendo exculpado.

\section{El secuestro de Heinrich Bauer}

Para la ALIU, el nombre original del traficante "Heinrich Bauer" era George Henri Delfanne, y era considerado integrante del servicio de espionaje alemán en España. En el informe, se relatan las acciones emprendidas desde Francia para la captura de Bauer, acusado de participar activamente en actos delictivos durante el régimen de Vichy. Su mención en el escrito, hace referencia al tráfico ilícito de obras de arte y antigüedades, que tenían como destino a España, sin embargo, por carecer de información, son pocos los argumentos en contra de Bauer.

\section{Wilhelm Gessmann, alias "Guillermo da Silva", y la miniatura de Goya}

Este caso gira en torno a la reclamación presentada por el español Juan Barri Massip, el 2 de febrero de 1947, quien solicitaba la recuperación de un pequeño retrato de 
Fernando VII, pintado por Francisco de Goya, y que estaba retenida en Lisboa por el CAC. Lo importante de resaltar, es que el señalado poseedor de la miniatura era "Guillermo da Silva", quien originalmente tenía como nombre Wilhelm Gessmann. El sujeto era representante de la librería Buchholz, que funcionaba como disfraz para las actividades de tráfico de arte. Esta Gessmann, trabajó con Goebbels y Von Ribbentrop, y en 1938 comerció con arte expropiado por los nazis. La librería tenia sedes en Berlín, Nueva York, y en 1943 en Lisboa, como puerta de salida de Europa. Aquí se aprecia la intrincada red internacional, que sin embargo, el informe pasa por alto.

Luego de la reclamación formal de España a los Aliados para conseguir la devolución de la miniatura, comenzó la controversia legal con las autoridades que no conseguían esclarecer el propietario de la pieza artística. Finalmente, tras afrontar procesos penales en Alemania y Austria, Gessmann, regresó a España, y tratando de evitar una deportación declaró que la miniatura pertenecía legalmente a Barri, con lo que se resolvió el caso aparentemente.

\section{Aduanas Pujol-Rubio, Antonio Puigdellivol y las tipográficas Neufville y Bauer}

Esta descripción en el informe, desarrolla el litigio entre empresas germanoamericanas. Las transacciones realizadas por los alemanes fueron bloqueadas por los estadounidenses, por pertenecer al bando del Eje, hasta 1949. Sin embargo, nunca se comprobó que dichas compañías tuvieran nexos directos con el expolio artístico o con alguna otra actividad ilegal.

\section{Baquera, Kusche y Martin, S. A.}

La agencia aduanera Baquera, Kusche y Martin, S. A. (Bakumar), fue puesta en la mira de los Aliados por su posible relación con Alois Miedl. Pero más allá de las simples sospechas, nunca se comprobó que existiera un vínculo directo entre estos. Bakumar, era una agencia aduanera que trabajaba con la Embajada alemana en España, por lo tanto, muchas de sus importaciones fueron objeto de bloqueos o investigaciones sobre sus objetos transportados. Bakumar, fue la encargada del movimiento del material para la exposición de artes gráficas alemanas de los siglos XIX y XX, realizada en Madrid y Barcelona entre 
1944 y 1945. Además, se le acusó de la destrucción de documentos de la Embajada alemana, todo ello sin sólidos sustentos.

\section{Galeristas y contrabandistas españoles que traficaban en España con arte expoliado}

Los documentos del AMAE y de la ALIU, señalan a varios ciudadanos españoles, que según informes, traficaban "objetos saqueados" principalmente entre Francia y España. En los relatos se menciona a Antonio Puigdellivol, Ángel "el saldista", Martín "de Bilbao", Apolinar Sánchez, Andrés Lázaro, y el alemán I. G. Farben. Todos señalados por ocultar y comerciar con arte expoliado por los nazis, sin que alguna investigación llegara a su final.

\section{Contrabandistas europeos y agentes alemanes en España}

Finalmente, el informe de 1998 declaraba lo siguiente: "Los informes de los servicios secretos norteamericanos dan cuenta de la existencia de un nutrido grupo de contrabandistas europeos y agentes alemanes que traficaron en España con obras de arte expoliadas. Sobre algunos de estos personajes, Lottier, Schiffman o Bauer, el AMAE contiene interesante documentación (...). El más importante era Paul Lindpaintner, que efectuó importantes transacciones con obras de arte expoliadas, la mayoría en nombre del marchante alemán Fritz Possenbacher, al que representaba en Paris. También mantuvo estrechos contactos con Dagobert Frey, historiador del arte alemán que dirigió el expolio artístico en Polonia, y fue socio de Johannes Hinrichsen, uno de los marchantes que compraban para Goering." 23 Sin embargo, no hay aclaración al respecto de estas informaciones.

Muchas de las operaciones comerciales fueron posibles por la presencia de redes contrabandistas entre Francia y España, donde se desenvolvían Heinrich Bauer, los hermanos Duval, Andrés Lázaro, Pierre Lottier y Graebener. El autor señala que gran parte del contrabando se posibilitó por la coexistencia de los regímenes de Franco y Pétain, pero no indica los mecanismos de esa relación.

\footnotetext{
${ }^{23}$ Miguel Martorell Linares, España y el expolio, 20.
} 
Finalmente, el profesor Martorell Linares, señala que España no es la excepción a las redes de contrabando que se desarrollaron en los países neutrales. Alude también, al poco material expoliado descubierto en España y que solo existen pruebas firmes del caso de los veintidós cuadros de Alois Miedl, vinculado a Göering. Sin embargo, aclara que posiblemente España fuera lugar de tránsito mas no de destino del arte saqueado y que, al margen del caso Miedl, los demás son de "poca monta". Esta afirmación resulta sorprendente, toda vez que la masa de documentación es enorme.

Del análisis de este informe se constatan varios aspectos. Por una parte, el autor no es experto en el tema, pese a que su dedicación es innegable. Su encargo oficial obedeció a la presión internacional ante las cada vez más contundentes pruebas contra la participación de España en el saqueo de Europa. Sin embargo, más allá de esto el informe aclara pocas cosas y deja más preguntas que respuestas. Pese a que se constatan nombres y elementos de análisis, en ningún caso hay señalamiento al régimen de Franco, algo que resulta sorprendente. Y lo es porque el apoyo a la Alemania de Hitler fue innegable durante la guerra, y solo después de 1943 Franco comenzó a separarse de su aliado ideológico ante las adversidades militares de Alemania. Pero la larga frontera entre España y Francia, así como los imponderables de una derrota muy evidente en 1944, hacían de España el lugar ideal para trasladar material robado, expoliado o confiscado, como parte del plan de ocultamiento del saqueo europeo. Igualmente, era muy obvio que España iba a ser un lugar de destino y/o tránsito para los jerarcas nazis, y las obras de arte eran capital fácilmente ocultable y trasportable. Por tal motivo, resulta extraño que el autor del informe no señale la necesaria complicidad de un régimen que, con su frontera abierta a Alemania, era la única autoridad que podía proteger, ayudar o facilitar semejantes labores.

Tal vez por ello, el profesor Martorell escribió en 2004 una revisión de su informe de 1998 en el que se hace una valoración más profunda de las implicaciones de España ${ }^{24}$. En este nuevo texto, se indica una obviedad conocida después de la guerra, pero ya fácilmente constatable gracias a las modernas investigaciones: Los historiadores Peter Harclerode y Brendan Pittaway sostienen que España fue el segundo país depositario de bienes expoliados por los nazis, por detrás de Suiza, incluidos entre ellos las obras de

${ }^{24}$ Miguel Martorell, “España y el expolio nazi de obras de arte”, Ayer, 55 (2004): 151-173. 
arte" $^{25}$. Pese a que no se va más allá, se evidencia cierto progreso en la valoración general del régimen de Franco, constatable al afirmar la escasa ayuda dada por el régimen a las investigaciones de los norteamericanos.

En este artículo de 2004 afirmaba que "hasta la fecha sólo han sido detectadas dos pinturas en España procedentes del expolio y las dos fueron adquiridas fuera del país en el último cuarto del siglo xx. Entre las piezas que pasaron a integrar en 1993 el Museo Thyssen-Bornemisza figuraba el cuadro de Camille Pisarro Rue de Saint Honoré después del mediodía) efecto de lluvia) comprado por los Thyssen en el mercado internacional de arte, en 1976. Antes de la guerra pertenecía al coleccionista alemán de origen judío Paul Cassirer, quien abandonó Alemania en 1938, pero antes se vio obligado a vender la pintura bajo coacción. Al tratarse de arte degenerado) la Gestapo lo subastó en Berlín en 1943 y luego desapareció hasta 1976. El otro cuadro es de André Masson -La familia en estado de metamorfosis- y lo adquirió en 1985 el Museo Nacional de Arte Reina Sofía por un millón de dólares." ${ }^{26}$ Esta afirmación va en la vía de detectar realmente la implicación de España y diversos actores en la "protección" del patrimonio confiscado en Europa, generando una mayor confianza de cara a futuras investigaciones.

Sin embargo, el camino emprendido a través de estos informes aún es largo, ya que hay gran resistencia a que Museos importantes o el propio estado español pueda verse salpicado por la inagotable cadena de investigaciones que se sucede. En 1998, 44 países se comprometieron a publicar una lista con las obras de instituciones públicas adquiridas desde 1933 y sospechosas de haber sido confiscadas por los nazis, aunque España, Francia e Italia aún no lo han hecho ${ }^{27}$.

\section{Conclusión}

A pesar del encomiable esfuerzo realizado, las conclusiones del informe no dejan entrever sino una parte de un problema aún mayor. Posiblemente de manera muy similar a

\footnotetext{
${ }^{25}$ Miguel Martorell, “España y el expolio nazi”, 169.

${ }^{26}$ Miguel Martorell, "España y el expolio nazi”, 173.

27 Andrea Rizi, Tras la pista del expolio nazi, El País, 25 octubre de 2006, http://elpais.com/diario/2006/10/29/cultura/1162072802_850215.html
} 
la Francia actual, en la que se trata de evitar la implicación del gobierno colaboracionista de Vichy con la deportación de judíos franceses, en España existe también un cierto silencio académico respecto del expolio artístico y el tránsito y/o depósito de obras en España durante y al final de la guerra. No nos cabe la menor duda de que este actitud refractaria con una verdad tan incómoda está relacionada directamente con la existencia cierta de obras de dudosa procedencia en los grandes museos de Arte de España. No sería difícil señalar algunas de ellas, aunque tampoco es el objetivo de este estudio, pero tampoco sería práctico ya que, como ha ocurrido en diversos museos de Estados Unidos o Gran Bretaña, tanto el gobierno como las autoridades museísticas ponen todas las trabas posibles para proceder a la restitución de los mismos. En mi opinión, esta es la mejor conclusión de por qué el informe analizado, pese a apuntar en una dirección correcta, solo muestra un aspecto superficial del asunto ante la más que posible dificultar de señalar a agentes y mecanismos españoles implicados en la desaparición de obras expoliadas durante la Segunda Guerra Mundial.

\section{Bibliografía}

Adam, Peter., AntonioPrometeo Moya, El arte del Tercer Reich. Barcelona: Tusquets, 1992.

Agosín, Marjorie. “Art Under Dictatorship”, Agni, n 31-32 (1990): 33-36.

Alford, Kenneth D.Hermann Göring and the Nazi art collection: the looting of Europe's art treasures and their dispersal after World War II. Jefferson: McFarland \& Company, Inc., Publishers, 2012.

Aly, Götz. La utopía nazi. Cómo Hitler compró a los alemanes. Barcelona: Crítica, 2008.

Baratieri, Daniela., Mark Edele, y Giuseppe Finaldi. Totalitarian Dictatorship: New Histories. New York: Routledge, 2013.

Feliciano, Héctor. El museo desaparecido: la conspiración nazi para robar las obras maestras del arte mundial. Barcelona: Planeta DeAgostini, 2006.

Ferguson, Niall. La guerra del mundo: los conflictos del siglo XX y el declive de Occidente (19041953). Barcelona: Debate, 2007.

Fest, Joachim C. Yo no: el rechazo del nazismo como actitud moral, Memorias y biografías (Taurus). Madrid: Santillana Ediciones Generales, 2007.

Fundación Carlos Ballesta López, http://www.fundacioncarlosballesta.com/blog/el-expolio-delpatrimonio-espanol-durante-la-guerra-de-independencia. 
Gray, Ronald. Hitler y los alemanes, Historia del mundo para jóvenes. Torrejón de Ardoz (Madrid): Akal, 1991.

Griffin, Roger. Modernismo y fascismo. La sensación de comienzo bajo Mussolini y Hitler. Madrid: Akal, 2010.

Hinz, Berthold., Joaquim Dols Rusiñol. Arte e ideología del nazismo. Valencia: Fernando Torres, 1978.

Kershaw, Ian. The Nazi State: An Exceptional State? New Left Review Limited, 1989.

. Totalitarianism revisited: Nazism and Stalinism in comparative perspective Cambridge: Cambridge University Press, 1994. . El mito de Hitler: imagen y realidad en el Tercer Reich. Barcelona: Crítica, 2012. La dictadura nazi. Madrid: Ed. Siglo XXI, 2004. . The Nazi dictatorship: Problems and perspectives of interpretation. Edward Arnold London, 1989.

Martorell Linares, Miguel. "España y el expolio nazi de obras de arte”, Ayer, 55 (2004): 151-173. Miguel. España y el expolio de las colecciones artísticas europeas durante la Segunda Guerra Mundial. Madrid: Ministerio de Asuntos Exteriores, 1998.

Nicholas, Lynn H. El saqueo de Europa: el destino de los tesoros artísticos europeos durante el Tercer Reich y la Segunda Guerra Mundial. Barcelona: Ariel, 2007.

Rizi, Andrea. Tras la pista del expolio nazi, El País, 25 octubre de 2006, http://elpais.com/diario/2006/10/29/cultura/1162072802 850215.html.

Samuel, Raphael. “Art and Power”, History Workshop Journal 41 (1996): 250-253.

Sebares, Francisco Erice. Guerras de la memoria y fantasmas del pasado: Usos y abusos de la memoria colectiva. Oviedo: Eikasia, 2009.

Werner, Alfred. “Ernst Barlach: Artist under a Dictatorship”. En Art Journal 22, n 2 (1962): 81-87. 